Ind. Health, 1966, 4, 98.

\title{
AN AUTOMATED METHOD FOR THE DETERMINATION OF ADRENALINE AND NORADRENALINE
}

\author{
Ayako KOJIMA \\ National Institute of Industrial Health, \\ Kizuki-Sumiyoshi, Kawasaki
}

(Received August 17, 1966)

\begin{abstract}
An automated method for the determination of adrenaline and noradrenaline in the eluate from alumina is presented. In this method, citrate was added to the alumina eluate to prevent the interference of aluminum hydroxide produced at neutral $\mathrm{pH}$ for the determination. For the differential estimation of the two catecholamines, two filter sets for activation and emission in fluorometry were used. The optimum concentrations of reagents for the determination were investigated.

Almost all catecholamines in the acetate buffer solution were recovered by the present method, and the recovery of catecholamines added to the alumina eluate of human urine was 90 to $95 \%$. Correlationship between the data obtained by the method of Euler and Lishajko1) and those by the present method was as follows; coefficients of correlation were 0.941 and 0.978 and regression lines were $y=0.86 x+4.4$ and $y^{\prime}=$ $1.05 x^{\prime}-2.4$ for adrenaline and noradrenaline respectively $\left(N=50, y y^{\prime}\right.$ for the automated method and $x, x^{\prime}$ for the manual method).
\end{abstract}

In the trihydroxyindole method for the determination of catecholamines, adrenaline and noradrenaline are oxidized by potassium ferricyanide, iodine or manganese dioxide to corresponding aminochromes, [and then these are rearranged to fluorescent trihydroxyindole derivatives in a strongly alkaline medium containing a reducing agent such as ascorbic acid. To estimate the two catecholamines separately, the differential $\mathrm{pH}$ or filter methods have generally been used.

Many of errors in these manual methods seem to be attributed to inaccurate timing of the addition of reagents and of the reading of the fluorescence intensity, accidental contamination from glassware, and instability of the alkali-ascorbic acid solution. These disadvantages should be eliminated if the method is applied to the automatic analysis.

Merrills2),3) and other authors4),5) have reported the automated procedures using two reducing agents --- ascorbic acid and thioglycolic acid --- to differentiate adrenaline and noradrenaline. It seemed, however, that when thioglycolic acid was used as reducing agent the sensitivity and the reproducibility were 


\section{AUTOMATED METHOD FOR DETERMINATION OF CATECHOLAMINES}

less than those in the use of ascorbic acid.

This paper contains a semi-automated method for the differential estimation of adrenaline and noradrenaline in human urine making use of two filter sets for activation and emission of their fluorescent derivatives and ascorbic acid as antioxidant.

\section{EXPERIMENTALS}

\section{Reagents}

1) Potassium ferricyanide, $0.01 \%$ in $0.1 \mathrm{M}$ acetate-ammonium buffer $(\mathrm{pH}$ 6.2).

2) Sodium hydroxide, $2.5 \mathrm{~N}$.

3) Ascorbic acid, $0.3 \%$.

4) Citrate buffer, $1 \mathrm{M}(\mathrm{pH} 6.2)$.

5) Acetate-ammonium buffer, 0.25 and $1 \mathrm{M}(\mathrm{pH} \mathrm{6.2)}$.

6) Standard solutions of catecholamines.

a. Stock standard solutions $(50 \mu \mathrm{g}$ of adrenaline $/ \mathrm{ml}$ and $100 \mu \mathrm{g}$ of noradrenaline/m1)

Dissolve $5.0 \mathrm{mg}$ of adrenaline free base or $19.1 \mathrm{mg}$ of noradrenaline bitartrate in $100 \mathrm{ml}$ of $0.1 \mathrm{~N}$ hydrochloric acid. Both solutions were stored under refrigeration.

b. Working standard solutions (A) $(0.2 \mu \mathrm{g}$ of adrenaline $/ \mathrm{ml}$ and $0.4 \mu \mathrm{g}$ of noradrenaline $/ \mathrm{ml}$ )

Dilute $0.4 \mathrm{ml}$ of the stock standard to $100 \mathrm{ml}$ with $0.01 \mathrm{~N}$ hydrochloric acid. These solutions were prepared daily.

c. Working standard solutions (B) $(20$ and $40 \mathrm{ng} / \mathrm{ml}$ for adrenaline and 40 and $80 \mathrm{ng} / \mathrm{ml}$ for noradrenaline)

Place 1.0 or $2.0 \mathrm{ml}$ of the working standard solution $\mathrm{A}, 2.5 \mathrm{ml}$ of $1 \mathrm{M}$ acetate buffer and $0.2 \mathrm{ml}$ of $1 \mathrm{M}$ citrate buffer in a $10 \mathrm{ml}$ volumetric flask, and fill up to $10 \mathrm{ml}$ with water. These standards were prepared immediately before use.

\section{Apparatus}

A Technicon standard AutoAnalyzer with a Turner fluorometer was used. The ultraviolet lamp used in the fluorometer was a Turner Blue Lamp (110-853). Two filter sets A and B were used, the former was consisted of an interference filter $405 \mathrm{~m} \mu$ as the primary filter and the Turner (8) sharp cut filter over $485 \mathrm{~m} \mu$ as the secondary one, and the latter was composed of a set of the Turner (47-B) narrow pass filter and (2A) sharp cut filter, which peaked at $436 \mathrm{~m} \mu$, and the Turner (2A-12) sharp cut filter over $510 \mathrm{~m} \mu$.

By placing two mirrors behind the flow cell at a right angle to each other, 


\section{A. KOJIMA}

the sensitivity of the detection system was increased about $60 \%$.

The fluorometer was set at maximum sensitivity with no slit for the filter set B and with slit 4 around the flow cell for the filter set A.

The sampler was run at 40 samples per hour and two aliquots of each sample were assayed successively for each filter set.

The flow diagram for the catecholamine determination is shown in Fig. 1.

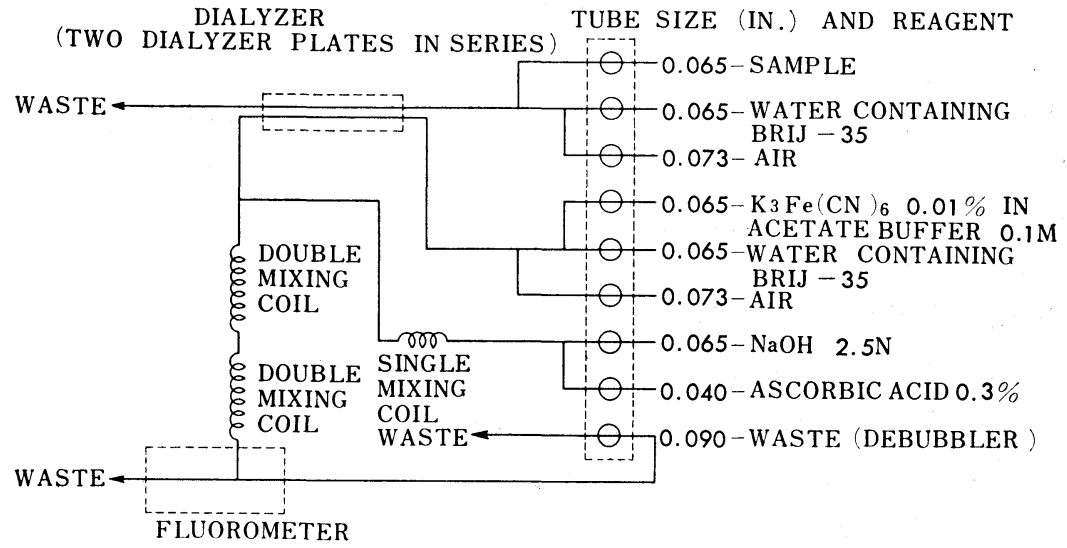

Fig. 1. Flow diagram for the determination of catecholamines.

\section{Procedure}

Isolation of catecholamines from human urine was carried out by the method of Euler and Lishajko.1) After the adsorption to alumina at $\mathrm{pH} 8.2$ and the elution with about $10 \mathrm{ml}$ of $0.25 \mathrm{M}$ acetic acid, $0.24 \mathrm{ml}$ of $1 \mathrm{M}$ citrate buffer was added to the eluate, $\mathrm{pH}$ was adjusted to 6.2 with ammonia, and the volume was adjusted to $12 \mathrm{ml}$ with $0.25 \mathrm{M}$ acetate buffer ( $\mathrm{pH} \mathrm{6.2).} \mathrm{These}$ samples were kept at about 0 to $4^{\circ} \mathrm{C}$ until the assay, and measured within the same day.

Each of these sample solutions and the working standard solutions B was placed in two successive sample cups. After all samples and standards had been estimated with the filter set A, the :ilter set was replaced with the other one and then the analysis with the filter set B was performed. The contents of adrenaline and noradrenaline were calculated from the fluorescence intensities with the two filter sets.

\section{RESULTS AND DISCUSSION}

When the alumina eluates which were added with ammonia for $\mathrm{pH}$ adjustment and standard solutions of catecholamines were run successively with the AutoAnalyzer, it was observed that the fluorescence intensity of the latter decreased gradually. And it was scarcely improved by the neutralization of the alumina eluate with phosphate and the centrifugation recommend- 


\section{AUTOMATED METHOD FOR DETERMINATION OF CATECHOLAMINES}

ed by Merrills.3) Therefore, some systemic trouble was assumed in the AutoAnalyzer during the assay.

Aluminum oxide is an efficient adsorbent for catecholamines. But, the eluate from alumina with acetic acid was demonstrated to contain 1.0 to 1.5 $\mathrm{mM} / 1$ of aluminum ion by the method of Davenport.6) When the eluate was adjusted to $\mathrm{pH} 6.2$ which is favourable for the oxidation of adrenaline and noradrenaline, colloidal aluminum hydroxide was formed. The reduction of the sensitivity might be attributable to the decrease of permeability of the dialyzer membrane caused by accumulation of the colloidal aluminum hydroxide. Method for preventing the production of colloidal aluminum hydroxide was considered. It is known that aluminum hydroxide does not precipitate in the presence of organic hydroxy-acids or hydroxy-compounds. In fact, the addition of $0.02 \mathrm{M} / 1$ of citrate to the alumina eluate prevented the troublesome precipitation of aluminum hydroxide at neutral $\mathrm{pH}$.

Since the quantity of catecholamines in biological substances is very small, determining method should be very"sensitive. Some device was tried to improve the sensitivity of fluorescence determination. Two mirrors were placed behind the flow cell in order to converge fluorescence light into the photomultiplier, and about $60 \%$ increase of the sensitivity was obtained by this device.

The behaviours of adrenaline and noradrenaline to various treatments were similar. To determine such substances, two different treatments have generally been used. Merrills2, 3) used the two stabilizing reagents, ascorbic

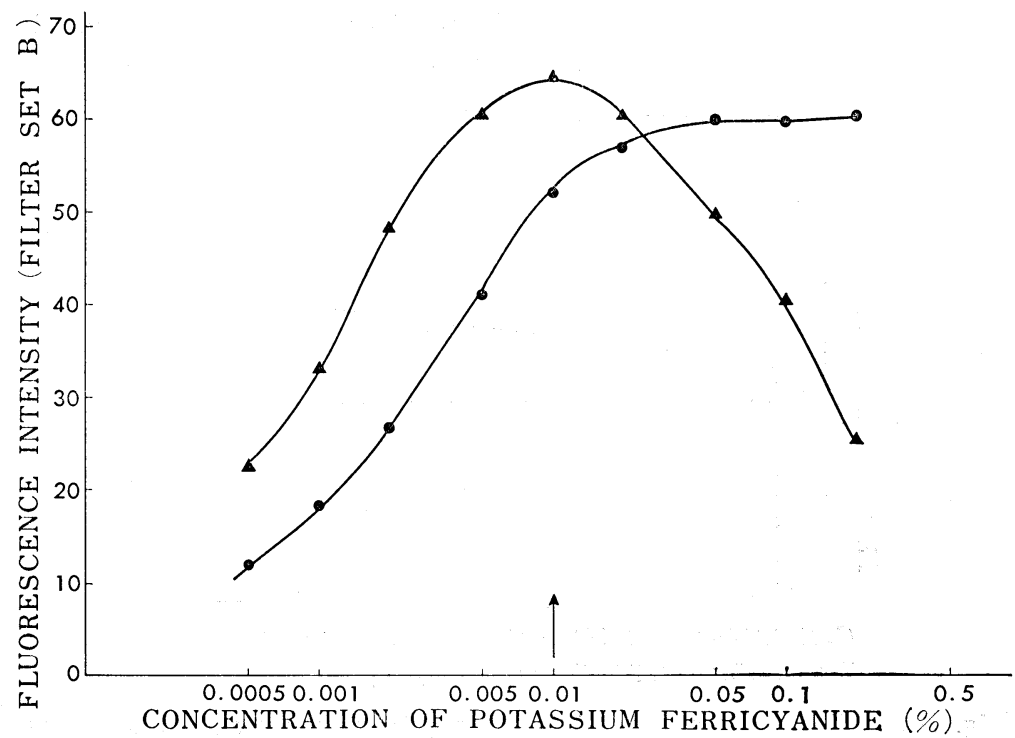

Fig. 2-1. Effect of potassium ferricyanide concentration on fluorescence intensities from adrenaline and noradrenaline.

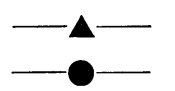

Adrenaline

Noradrenaline 


\section{A. KOJIMA}

acid and thioglycolic acid. The fluorescence intensities from catecholamines treated with the latter antioxidant were, however, weak and dropped gradually with time in contrast to those with the former reagent. Therefore, in this study ascorbic acid was used as antioxidant and two filter sets to determine adrenaline and noradrenaline were used.

The effects of the concentrations of potassium ferricyanide, acetate buffer, sodium hydroxide, ascorbic acid and citrate on the fluorescence intensities from adrenaline and noradrenaline are shown in Fig. 2. From these data the optimum condition for the maximum sensitivity for adrenaline which was ordinarily found in a smaller quantity than noradrenaline in human urine was settled as shown in Fig. 1.

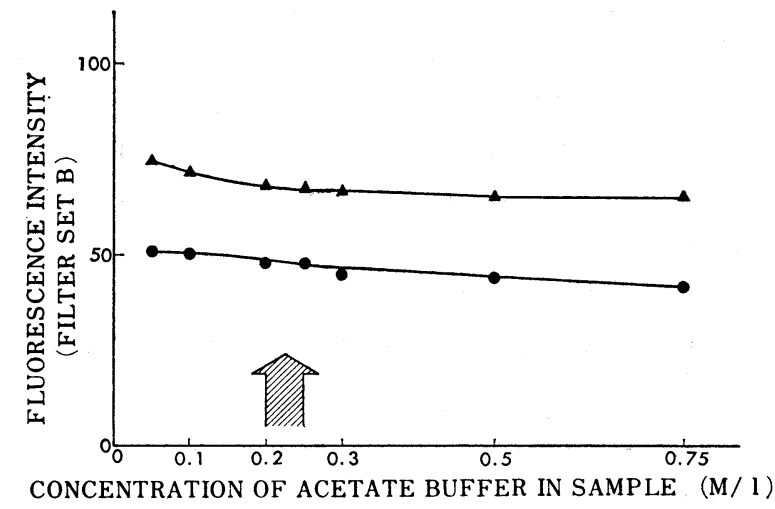

Fig. 2-2. Effect of concentration of acetate buffer in sample on fluorescence intensity from adrenaline and noradrenaline.
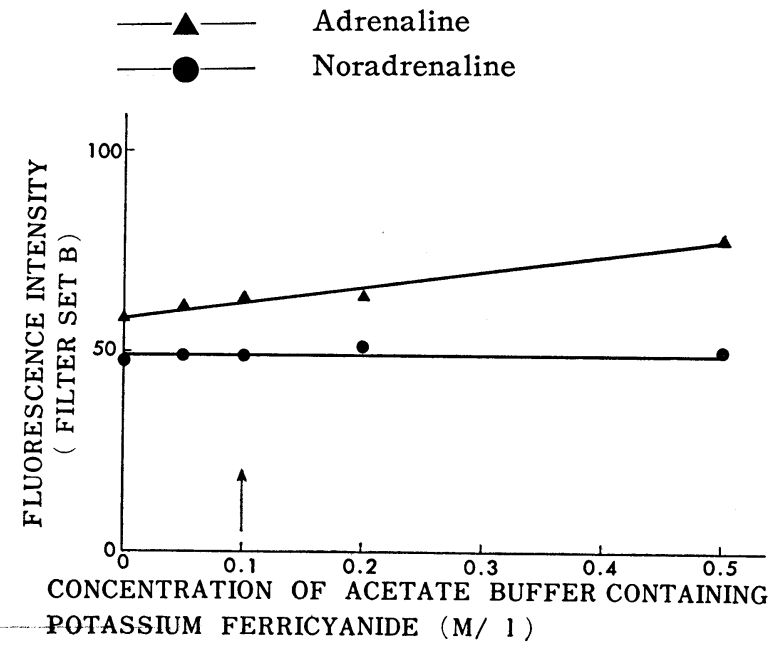

Fig. 2-3. Effect of concentration of acetate buffer containing potassium ferricyanide on fluorescence intensities from adrenaline and noradrenaline.

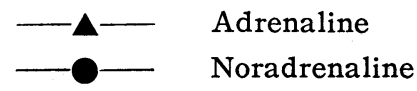




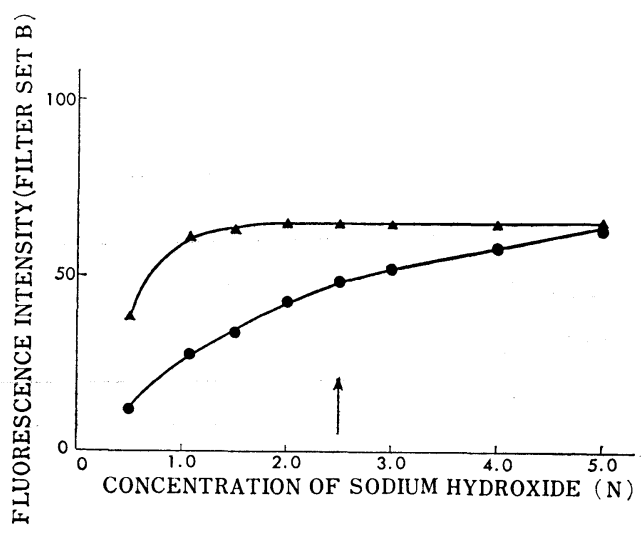

Fig. 2-4. Effect of sodium hydroxide concentration on fluorescence intensities from adrenaline and noradrenaline.
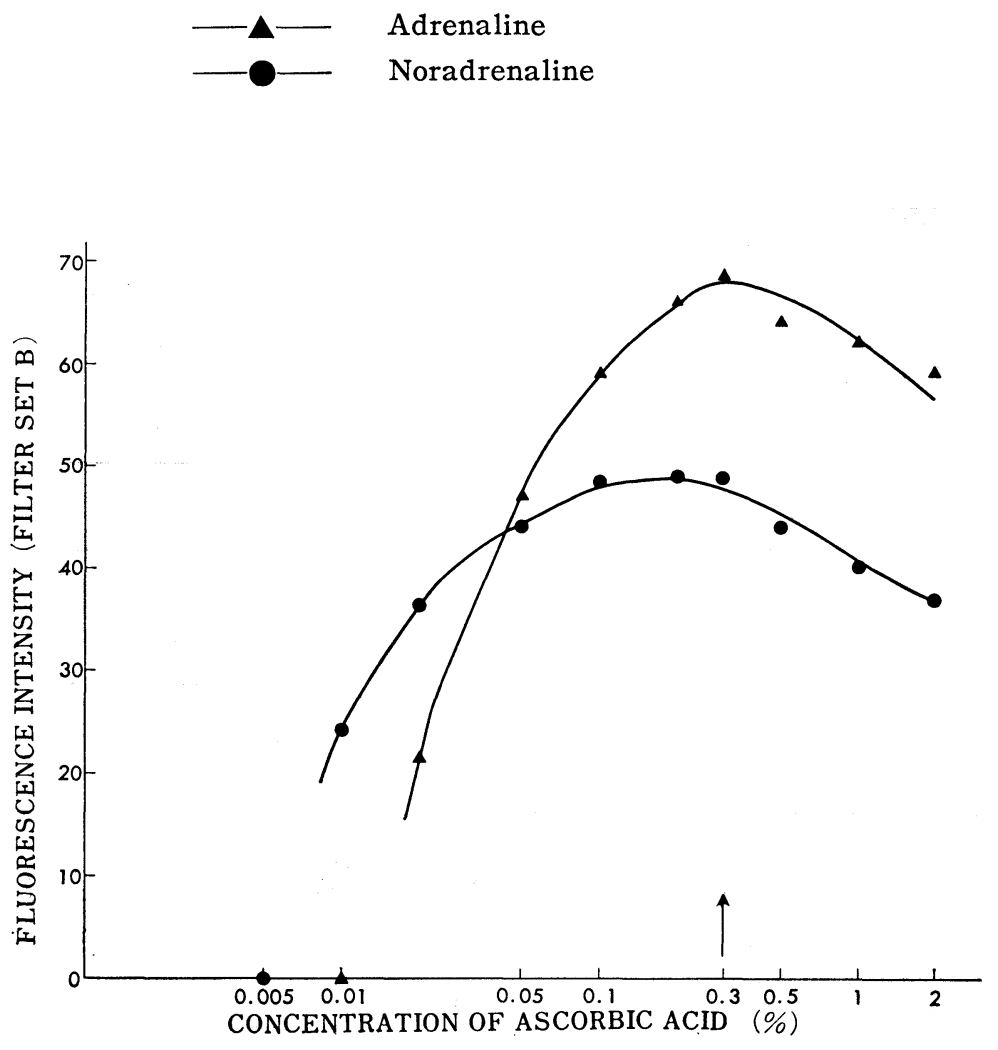

Fig. 2-5. Effect of ascorbic acid concentration on fluorescence intensities from adrenaline and noradrenaline.

$\begin{array}{ll}- & \text { Adrenaline } \\ - & \text { Noradrenaline }\end{array}$ 


\section{A. KOJIMA}

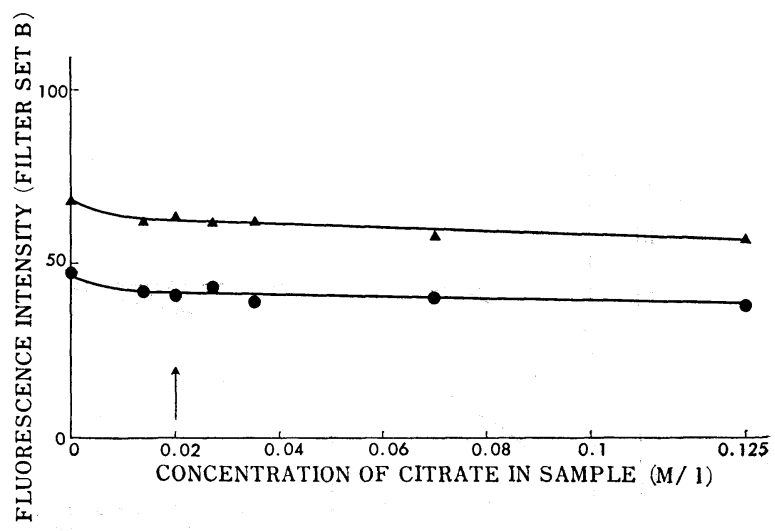

Fig. 2-6. Effect of citrate concentration in sample solution on fluorescence intensities from adrenaline and noradrenaline.
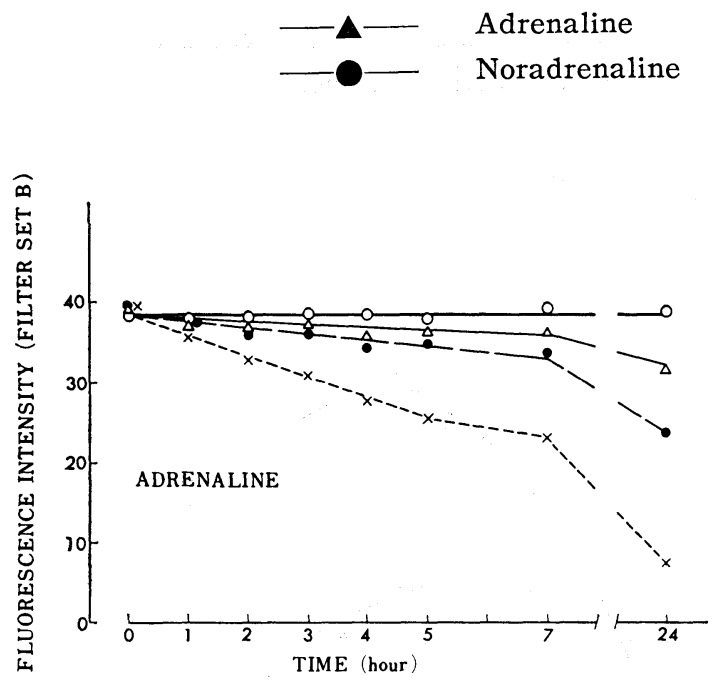

Fig. 3-1. Stability of adrenaline and noradrenaline in acetate buffer at $\mathrm{pH}$ 6.2 . $-\mathrm{O}-$ in an ice bath.

$-\triangle-$ in a refrigerator (at about $\left.2 \sim 4^{\circ} \mathrm{C}\right)$

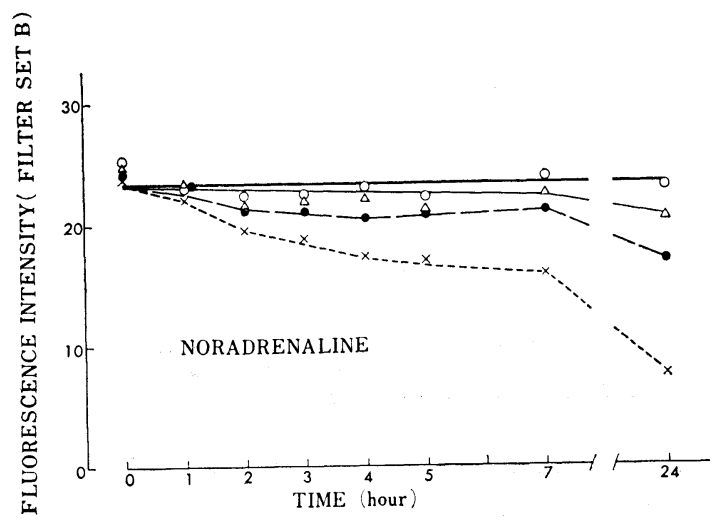

- at $15^{\circ} \mathrm{C}$. $\ldots \ldots \times \cdots . . \quad$ at $30^{\circ} \mathrm{C}$. 


\section{AUTOMATED METHOD FOR DETERMINATION OF CATECHOLAMINES}

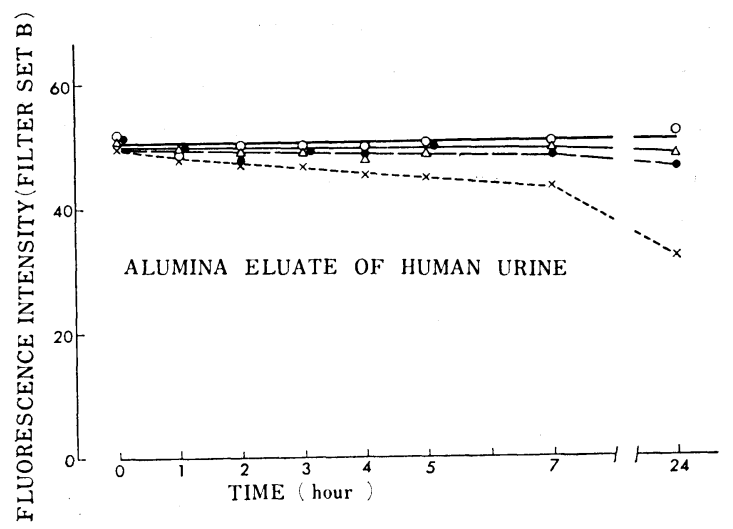

Fig. 3-2. Stability of urine eluate in acetate buffer at $\mathrm{pH} 6.2$.

$\begin{array}{ll}- & \text { in an ice bath. } \\ - & \text { in a refrigerator (at about } 2 \sim 4^{\circ} \mathrm{C} \text { ) } \\ \ldots \ldots \times \cdots \cdots & \text { at } 15^{\circ} \mathrm{C} .\end{array}$

Fig. 3 shows the stabilities of catecholamines in the working standard solution $\mathrm{B}$ and the urine eluate adjusted to $\mathrm{pH} 6.2$ under various conditions. The amines seemed to be stable in an ice bath or in a refrigerator at 0 to $4^{\circ} \mathrm{C}$ for several hours at the neutral $\mathrm{pH}$. Catecholamines in the alumina eluate, of which $\mathrm{pH}$ was not adjusted, were hardly destroyed within at least one week if stored under refrigeration, as seen in Fig. 4.

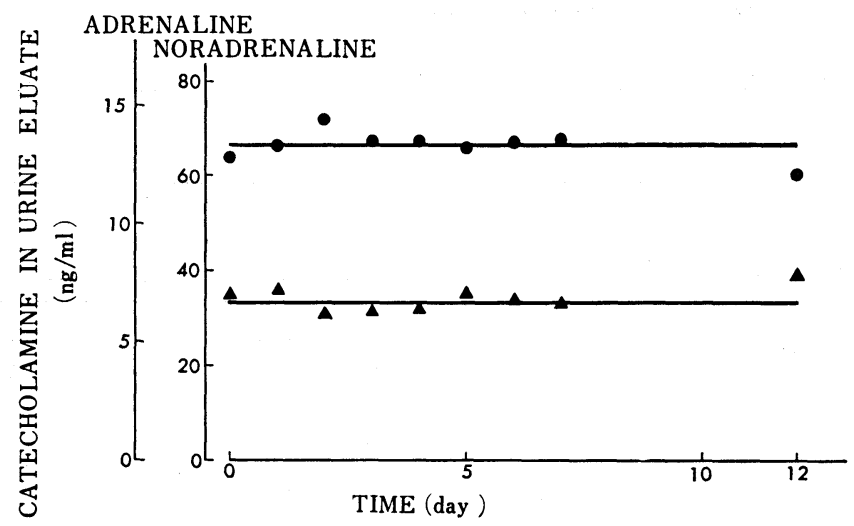

Fig. 4. Stabilities of catecholamines in an acidic urine eluate under refrigeration.

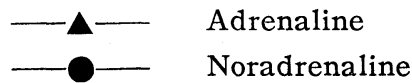




\section{A. ǨOJIMA}

Linear relationship between concentration of catecholamine and its fluorescence intensity by the present method is shown in Fig. 5. Result of differential determination of adrenaline and noradrenaline in mixture is given in Table 1. This was a recovery of adrenaline and noradrenaline from acetate buffer solution added with the both. Recovery seemed to be satisfactory. Mean recoveries of adrenaline (10 or $20 \mathrm{ng} / \mathrm{ml}$ ) and noradrenaline $(20$ or $40 \mathrm{ng} / \mathrm{ml}$ ) added to the alumina eluates of urines were 94.6 and $91.1 \%$, and unbiased variances of those were 19.0 and $51.4(\mathrm{~N}=22)$, respectively.

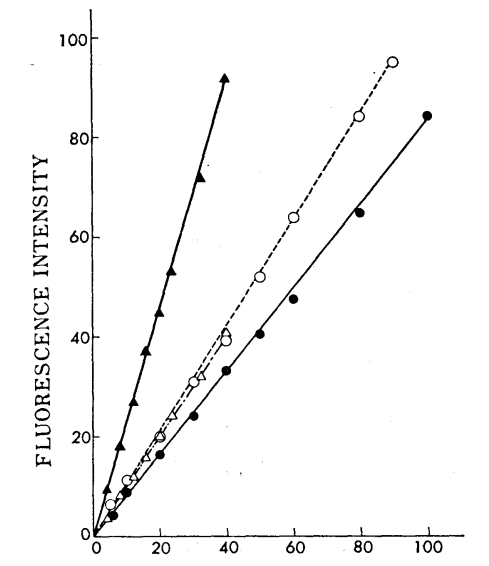

CONCENTRATION OF CATECHOLAMINE (ng/ml)

Fig. 5. Calibration curves for adrenaline and noradrenaline.

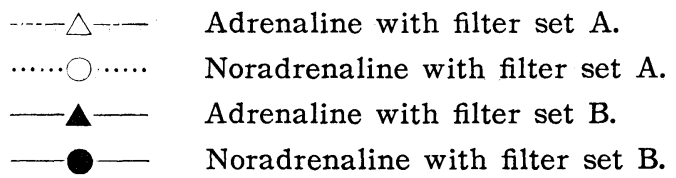

Table 1. Differential estimation of adrenaline and noradrenaline in acetate buffer solution. $(\mathrm{ng} / \mathrm{ml})$

\begin{tabular}{|c|c|c|c|}
\hline \multicolumn{2}{|c|}{ Added } & \multicolumn{2}{c|}{ Found } \\
\hline Noradrenaline & Adrenaline & Noradrenaline & Adrenaline \\
\hline 15.0 & 2.5 & 15.4 & 2.5 \\
15.0 & 7.5 & 15.2 & 7.5 \\
15.0 & 12.5 & 14.2 & 13.2 \\
15.0 & 17.5 & 15.3 & 17.3 \\
15.0 & 20.0 & 15.2 & 19.6 \\
20.0 & 10.0 & 20.5 & 9.6 \\
\hline
\end{tabular}

In the manual trihydroxyindole method for the determination of catecholamines, fluorescence intensity of the non-oxidized solution has widely been used as blank value and this value is almost equal to that of reagent blank. 


\section{AUTOMATED METHOD FOR DETERMINATION OF CATECHOLAMINES}

But the non-oxidized blank value of catecholamine solution in the automated method, in which reagents were added in the same order as in the manual method, changed with the concentration of added amine. It was so, more or less, even if ascorbic acid was added to the stream of sample before the dialyzer to prevent spontaneous oxidation of catecholamines in the dialyzer of $37^{\circ} \mathrm{C}$. This disagreement between non-oxidized blank values in the two methods would be due to some difference of condition in procedure. Nonoxidized blank should not be used unless this problem is solved. On the other hand, the value of faded blank of catecholamine solution was small enough to be neglected as compared with stabilized value and its value of alumina eluate of human urine was less than $2 \%$ of the stabilized value. The faded blanks of catecholamines in standard solution and urine eluate were regarded as almost negligible compared with other errors in the method. In the present method, therefore, no blank was measured.

For precise determination of catecholamines, especially in consideration of the uncommon appearance of shoulder-shaped peak, each sample was measured twice successively.

To confirm whether by this proposed method catecholamines only and no other similar substances were determined, urine eluate was fractionated with Amberlite IRC-50 by the method of Kirshner.7) There were observed no peaks other than those of adrenaline and noradrenaline as shown in Fig. 6. Table 2 gives the fluorescence intensities of catecholamine homologues by this method. Besides adrenaline and noradrenaline, isopropylnoradrenaline gives a strong fluorescence, but its content in normal human urine is not so much as to influence the determination of adrenaline and noradrenaline.8) Therefore, the fluorescence from the urine eluate by the present method was considered to originate in adrenaline and noradrenaline.

Catecholamines in fifty urine eluates were determined by the manual method of Euler and Lishajko1) and the present one, and a signi:îcant correla-

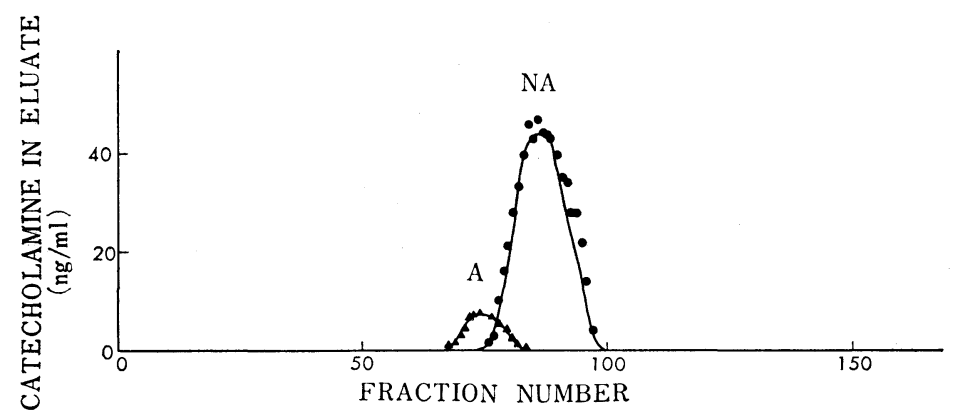

Fig. 6. Separation of adrenaline and noradrenaline in an alumina eluate of human urine with Amberlite IRC-50.

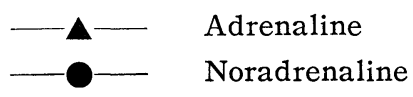




\section{A. KOJIMA}

Table 2. Fluorescence intensity from catecholamine homologues by the present method.

\begin{tabular}{|l|c|c|}
\hline \multirow{2}{*}{ Substances } & \multicolumn{2}{|c|}{ Relative fluorescence intensity per 1 ng } \\
\cline { 2 - 3 } & Filter set A & Filter set B \\
\hline p-Sympathol tartrate & 0.00 & 0.00 \\
p-Hydroxyphenyl aminoethanol & 0.00 & 0.00 \\
Dopamine & 0.00 & 0.00 \\
Dopa & 0.02 & 0.01 \\
Metanephrine & 0.00 & 0.00 \\
Normetanephrine & 0.00 & 0.00 \\
Isopropylnoradrenaline & 0.47 & 0.00 \\
Adrenaline & 0.74 & 1.04 \\
Noradrenaline & 0.54 & 1.58 \\
\hline
\end{tabular}

tion between the data obtained by the two methods was found on each amine. Coefficients of correlation were 0.941 and 0.978 , and regression lines were $\mathrm{y}=$ $0.86 \mathrm{x}+4.4$ and $\mathrm{y}^{\prime}=1.05 \mathrm{x}^{\prime}-2.4$ for adrenaline and noradrenaline respectively $\left(y, y^{\prime}\right.$ for the automated method and $x, x^{\prime}$ for the manual method).

Consequently, an accurate semi-automated determination of adrenaline and noradrenaline in human urine was made possible by the addition of small amounts of citrate to the eluate after the purification by adsorption with alumina.

\section{ACKNOWLEDGEMENT}

The author is indebted to Dr. Kazuko Mori for her kind guidance throughout the course of this work.

\section{REFERENCES}

1) Euler, U. S. von and Lishajko, F. (1961). Acta Physiol. Scand., 51, 348.

2) Merrills, R. J. (1962). Nature, 193, 988.

3) Merrills, R. J. (1963). Anal. Biochem., 6, 272.

4) Fiorica, V. (1965). Clin. Chim. Acta, 12, 191.

5) Robinson, R. L. and Watts, D. T. (1965). Clin. Chem., 11, 986.

6) Davenport, W. H. (1949). Anal. Chem., 21, 710.

7) Kirshner, N. and Goodall, Mc C. (1957). J. Biol. Chem., 226, 207.

8) Peyrin, L. (1964). Rev. Franc. Etudes Clin. Biol., 9, 1096; (1965). Chem. Abst., 62, 10809. 